\title{
Pharmacovigilance of the Covid19 therapeutic protocol : Experience of the Hassan II University Hospital of Fez, Morocco and analysis of national and international data
}

\author{
Hasnae HOUMMANI1,2*,Hajar MOURABITI1,2, mohamed CHEBAIBI1,2, Sanae ACHOUR1,2 \\ 1 Service de toxico-pharmacologie, CHU Hassan II, Fès,Morocco \\ 2 laboratoire de recherches biomédicales et translationnelle, Faculté de médecine et de pharmacie, USMBA, Fès, Morocco \\ *hasnae0310@gmail.com
}

\begin{abstract}
Faced with the pandemic related to the dissemination of the new Coronavirus and the health emergency, Morocco decided to treat patients with Covid-19 with Hydroxychloroquine (HCQ) or Chloroquine (CQ), associated with Azithromycin (AZM) according to a standardized therapeutic scheme, an off-label indication that required pharmacovigilance monitoring to ensure the safety of treated patients. Objective. To present the experience of the Hassan II University Hospital of Fez concerning the management of adverse events of the Covid19 therapeutic protocol. A notification form was made available to the nursing staff to be filled in for any adverse reaction (ADR) observed after the treatment was taken. A daily collection and in-depth analysis was performed. We present the results of the analysis of the data collected in our training between April 21 and August 22, 2020, discussing them with data from national and international databases. 102 ADR cases were collected out of 915 patients hospitalized at the UHC for Covid19 during this period with a prevalence of 11\%. 23 patients had underlying defects. The incriminating protocol contained CQ in 55.8\% and HCQ in 44.2\%. The mean age of the patients was $40.83 \pm 17.1$ years (18 to 86 years) with a M/F sex ratio of 0.92. The mean time to onset was 3 days (range 1-6 days). The most noted ADRs were digestive, cardiac and neurological. 14 cases were severe (one QT prolongation), 6 of which required transfer to an intensive care unit. The course of action adopted was the restoration of corrective treatment with 12 cases of treatment discontinuation and 8 cases of switching to 2 nd line treatment.
\end{abstract}

\section{Introduction}

Faced with the pandemic related to the dissemination of the new Coronavirus and the health emergency, Morocco, in addition to preventive measures to limit the spread, has instituted a scientific-technical advisory committee that was adopted on March 21, 2020 recommendations for the management of confirmed positive patients. Morocco, like many countries around the world, has decided to treat patients with Covid-19 with a therapeutic protocol containing Hydroxychloroquine (HCQ) or Chloroquine (CQ), associated with Azithromycin (AZM) according to a standardized therapeutic scheme [1]. This is an off-label indication that required pharmacovigilance monitoring to ensure the safety of treated patients. In parallel with the implementation of the protocol, recommendations have been proposed : before the beginning of the protocol and in case of adverse events when an adverse event occurs (preventive and corrective actions). Since the launch of the therapeutic protocol, our institution has been involved in the actions carried out at the national level by the Antipoison and Pharmacovigilance Center of Morocco (CAPM), in collaboration with the Directorate of Epidemiology and Fight against Diseases, who have instituted reinforced surveillance of the adverse effects (AE) of these drugs [2].

The objective is to study the adverse effects of these drugs in this new indication, evaluate the benefit/risk ratio of 
these drugs, and ensure better safety of treated patients. At our center, we have instituted reinforced pharmacovigilance of these therapeutic protocols. A notification form has been made available to all the nursing staff (doctors, nurses...) taking care of these patients, including information on the patient, description of the adverse reaction, the incriminated drug, and the notifying staff. An in-depth analysis of these reports with an imputability study assessing the causal link between the drug and the occurrence of the adverse reaction was carried out.

\section{Objectif}

To expose the experience of the Hassan II University Hospital of Fez in the management of adverse events of the Covid19 therapeutic protocol.

\section{methods}

A notification form was made available to the nursing staff to be filled in for any adverse reaction (ADR) observed after the treatment was taken. A daily collection and indepth analysis were carried out. The results of the analysis of the data collected in our training between April 21 and August 22, 2020, are presented.

\section{Results}

102 cases of adverse events were collected out of 915 patients hospitalized at Hassan II University Hospital of Fez for Covid19 during this period with a prevalence of $11 \% .23$ patients had serious pathological antecedents: 10 hypertension, 6 diabetes, 1 heart disease, 2 chronic hemodialysis patients, 2 patients under chemotherapy, 1 hyperthyroid, 1 hepatitis B under treatment. The incriminating protocol contained CQ in 55.8\% and HCQ in $44.2 \%$. The mean age of the patients was $40.83 \pm 17.1$ years (18 to 86 years) with an $\mathrm{M} / \mathrm{F}$ sex ratio of 0.92. The mean time to onset of ADRs was 3 days with extremes ranging from 1 to 6 days. The most common ADRs were digestive, cardiac, and neurological (Table 1). 14 of them were severe, represented by QT prolongation, including 6 cases that required transfer to an intensive care unit. The severe cases had a history of diabetes in 11 of them, hypertension in 2 cases, a patient under chemotherapy, a chronic hemodialysis patient, a hepatitis B patient under treatment. The course of action adopted was the restoration of corrective treatment with 12 cases of discontinuation of treatment and 8 cases of switching to second-line treatment based on the combination of Lopinavir and Ritonavir.

Table 1 : Adverse events by Class System-Organ

\begin{tabular}{|c|l|l|}
\hline \multicolumn{1}{|c|}{ ADRs } & \multicolumn{1}{|c|}{ N } & \multicolumn{1}{c|}{$\%$} \\
\hline Gastrointestinl disorders & $\mathbf{5 5}$ & $\mathbf{5 3 , 9}$ \\
Vomiting / nausea & 11 & 10,8 \\
Diarrhoea & 34 & 33,3 \\
Abdominal pain & 5 & 4,9 \\
Epigastralgia & 4 & 3,9 \\
Constipation & 1 & 0,98 \\
\hline
\end{tabular}




\begin{tabular}{|c|c|c|}
\hline $\begin{array}{l}\text { Cardiac disorders } \\
\text { ECG QT prolonged } \\
\text { BAV }\end{array}$ & $\begin{array}{l}16 \\
14 \\
2\end{array}$ & $\begin{array}{l}15,68 \\
13,7 \\
1,96\end{array}$ \\
\hline $\begin{array}{l}\text { Hepatobiliary disorders } \\
\text { Transaminse increased }\end{array}$ & $\begin{array}{l}2 \\
2\end{array}$ & 1,96 \\
\hline $\begin{array}{l}\text { Eye disorders } \\
\text { Ocular migraine } \\
\text { Vision blurred }\end{array}$ & $\begin{array}{l}2 \\
1 \\
1\end{array}$ & 1,96 \\
\hline $\begin{array}{l}\text { Skin and subcutanous tissue disorders } \\
\text { Rash } \\
\text { Pruritic lesions }\end{array}$ & $\begin{array}{l}4 \\
2 \\
2\end{array}$ & 3,9 \\
\hline $\begin{array}{c}\text { Psychiatric disorders } \\
\text { Panic attacks } \\
\text { Insomnia }\end{array}$ & $\begin{array}{l}3 \\
1 \\
2\end{array}$ & 2,94 \\
\hline $\begin{array}{l}\text { Nervous system disorders } \\
\text { Headache } \\
\text { Dizziness } \\
\text { Hypoacusis } \\
\text { Tingling of the limbs }\end{array}$ & $\begin{array}{l}\mathbf{1 0} \\
6 \\
1 \\
1 \\
2\end{array}$ & 9,8 \\
\hline $\begin{array}{l}\text { Atteintes hématologiques } \\
\text { Anemia } \\
\text { Pancytopenia }\end{array}$ & $\begin{array}{l}3 \\
2 \\
1\end{array}$ & 2,94 \\
\hline
\end{tabular}

\section{Discussion}

On March 11, 2020, and given the alarming levels of spread and severity of the disease, the WHO had qualified COVID-19 as a pandemic [3]. Each country has advocated protocols that include probabilistic treatments pending the development of new treatments. Chloroquine (CQ) and hydroxychloroquine (HCQ) have been proposed in several studies, but the results were not conclusive regarding their efficacy and safety [4,5]. On March 28, 2020, the Food and Drug Administration (FDA) approved the emergency use of CQ and HCQ to treat adults and adolescents who weigh $50 \mathrm{~kg}$ or more and are hospitalized with COVID-19 [6]. CQ and HCQ are two drugs that have been used for over 70 years and have well-established safety profiles and their adverse effects at therapeutic doses or in case of overdose are well known [7]. Adverse events reported were more frequent with CQ than with HCQ. The reactions observed were all labeled in the summary of product characteristics of CQ, HCQ, or AZM. The majority were not severe and were treated by changing the drug, reducing the dose, or administering symptomatic therapy.

On April 14, 2020, the ANSM (National Agency for the Safety of Medicines and Health Products) published its first pharmacovigilance report on hydroxychloroquine when used in COVID-19 patients. In general, the data collected indicate that reports under these conditions of use are consistent with the known toxicity profile of these drugs (hepatotoxicity, nephrotoxicity, retinal damage, or 
cardiovascular disorders). The majority of cardiovascular event reports concern chloroquine and hydroxychloroquine, either alone or in combination with another drug (notable azithromycin) [8].

On the national scale, the median age of the patients was 41 (29 - 55) years. The sex ratio $\mathrm{M} / \mathrm{F}$ was $0.75 .38 \%$ of the patients (137 cases) with ADRs had comorbidity as a contributing factor: diabetes for 43 patients, arterial hypertension for 34 , heart disease for 12 , asthma for 10 , drug addiction for 6 and renal insufficiency for 4 patients, although a patient may have one to three associated pathologies. Among the 483 ADR cases, 15\% were considered serious. Chloroquine was suspected in 235 cases (48.7\%) and Hydroxychloroquine in 248 cases (51.3\%). These drugs were associated with Azithromycin in all cases. CQ and HCQ were discontinued in 73 patients (15.1\%). 920 adverse events were reported, with an average of two AEs per patient. The most commonly reported AEs were gastrointestinal (65.6\%), nervous system (19.5\%), psychiatric (16.1\%), cardiac (12.2\%) and ocular $(12.0 \%)$ [9]. Our results were consistent with national data but contrasted with the WCC-UMC report, where the most frequently reported ADR associated with both CQ or HCQ was QT interval prolongation on the electrocardiogram. As the WCC-UMC report was based on spontaneous reports related to COVID-19 from VigiBase, the WHO global database of individual case safety reports [10].

The CAPM has received reports of drug errors (dose, interval), failure to follow the treatment regimen, and drug interactions. These errors could lead to potentially serious adverse events in patients due to drug overdose or pharmacokinetic or pharmacodynamic changes.

\section{Conclusion}

Adverse events associated with the use of chloroquine and hydroxychloroquine in the treatment of Covid 19 are frequent and require intensive monitoring of all patients receiving these drugs to detect risk factors that may increase the severity of these adverse events or make them life-threatening

\section{References}

1- Protocole de prise en charge des patients des patients atteints de Covid-19 et leurs contacts. Circulaire n²3/DELM/2020 du 24 Mars 2020 mise à jour le 14 avril

2- Le sulfate de Chloroquine (Nivaquine $\AA$ ) et le Sulfate d'Hydroxychloroquine (Plaquénilß) dans le protocole thérapeutique de l'infection par le virus SARS-CoV-2 Recommandations du Centre Antipoison et de Pharmacovigilance du Maroc CAPM. http://www.covidmaroc.ma/Documents/202 0/coronavirus/PS/Note_CAPM_CQHCQ_Maicompresse\%CC\%81.pdf

3- COVID-19 - Chronologie de l'action de I'OMS.

https://www.who.int/fr/news/item/27-042020-who-timeline---covid-19. Accessed juin, 142021

4- Moore N. Chloroquine for COVID-19 Infection. Drug Safety 2020;43:393-394; https://doi.org/10.1007/s40264-020-009334

5- Cortegiani A, Ippolito M, Ingoglia G, Iozzo P, Giarratano A, Einav S. Update I. A systematic review on the efficacy and safety of chloroquine/hydroxychloroquine for COVID19, Journal of Critical Care 2020;59:176190; https://doi.org/10.1016/j.jcrc.2020.06.019.

6- Food and Drug Administration. Review of Hydroxychloroquine and Chloroquine. 2020; 
https://www.accessdata.fda.gov/drugsatfda _docs/nda/2020/OSE\%20Review_Hydroxyc hloroqui

e-Cholorquine $\% 20$ \%2019May2020_Redacted.pdf. accessed 22 December 2020.

7- Chloroquine et hydroxychloroquine dans la prise en charge du COVID-19. https://www.elsevier.com/frfr/connect/med ecine/chloroquine-et-hydroxychloroquinedans-la-prise-en-charge-du-covid-19.

8- COVID-19: PREMIÈRES DONNÉES DE PHARMACOVIGILANCE POUR L'HYDROXYCHLOROQUINE ET LOPINAVIR/RITONAVIR. Par DAVID PAITRAUD - date de publication : 14 avril 2020.

https://www.vidal.fr/actualites/24741-

covid-19-premieres-donnees-de-

pharmacovigilance-pour-I-

hydroxychloroquine-et-lopinavir

ritonavir.html

9- Bulletin épidémiologique COVID 19 édité par le Centre National des Opérations d'Urgences de Santé Publique/Direction de I'Épidémiologie ET EDE Lutte CONTRE LES Maladies. Numéro 8 du 30/06/2020. https://www.sante.gov.ma/Publications/Bull ten_pidmiologique/3-COVID19\%20\%20Bulletin\%20\%C3\%A9pid\%C3\% A9miologique\%20(30-06-2020).pdf

10- World Health Organisation. Descriptive analysis of COVID-19-related spontaneous reports from VigiBase: interim results. 2020; . https://www.who.int/medicines/regulation/ medicines-safety/COVID19-PVupdate6. pdf?ua=1. Accessed 30 July 2020. Accessed 14 juin 2021. 